\title{
The Hyponatremia Epidemic: A Frontier Too Far?
}

\author{
Angela J. Drake-Holland ${ }^{1 *}$ and Mark I. M. Noble ${ }^{2}$ \\ 'School of Pharmacy and Life Sciences, The Robert Gordon University, Aberdeen, UK, ${ }^{2}$ Department of Medicine and \\ Therapeutics, University of Aberdeen, Aberdeen, UK
}

Hyponatremia is the most common electrolyte abnormality and is often neglected, especially in elderly and seemingly terminal patients. Hyponatremia can be asymptomatic or can cause symptoms ranging from nausea and lethargy to convulsions and coma. This condition has become increasingly common over time with a similar time course to the increase in adoption of low salt diets. The popularization of low salt may not be justified in people with normal kidney function in whom the compatible statistically based evidence that salt causes hypertension has been challenged by experimental evidence to the contrary.

Keywords: sodium, salt, elderly, kidney function, hypertension

\section{KEY POINTS}

OPEN ACCESS

Edited by:

Junjie Xiao,

Shanghai University, China

Reviewed by:

Thomas Kahan,

Karolinska Institutet, Sweden

Tao Li Chan,

Nanjing Medical University, China

${ }^{*}$ Correspondence: Angela J. Drake-Holland drake-holland@rgu.ac.uk

Specialty section:

This article was submitted to General Cardiovascular Medicine, a section of the journal Frontiers in Cardiovascular Medicine

Received: 22 July 2016 Accepted: 27 September 2016 Published: 07 October 2016

Citation:

Drake-Holland AJ and Noble MIM (2016) The Hyponatremia Epidemic: A Frontier Too Far?

Front. Cardiovasc. Med. 3:35. doi: 10.3389/fcvm.2016.00035
1. Hyponatremia is the most common electrolyte abnormality and is often neglected, especially in elderly and seemingly terminal patients.

2. Hyponatremia can be asymptomatic or can cause symptoms ranging from nausea and lethargy to convulsions and coma.

3. The increase in prevalence over time has a similar time course to the increase in adoption of low-salt diets.

4. Investigation into the electrolyte status of individual subjects would be expected to reveal the suitability or otherwise of dietary salt intake.

5. If policy 4 above is adopted, it may be necessary to withdraw recommendation of low-salt diet to the entire population.

6. Investigation into the electrolyte status of individual subjects would also be advisable in view of the lack of experimental evidence in normal people that high salt raises blood pressure and that hypertensive patients have normal body sodium.

\section{HYPONATREMIA}

A normal concentration of sodium ions $\left(\mathrm{Na}^{+}\right)$in plasma and extracellular fluid is essential for nerve and muscle electrical conduction $(1,2)$. If dietary salt intake does not equal or exceed salt loss in urine and sweat, a fall in $\mathrm{Na}^{+}$below concentrations that allow normal function will occur (2). This condition (hyponatremia) causes dysfunction of brain and body; much Alzheimer's disease has been attributed to hyponatremia (3). In a hot country, such as Uganda, in which there is a high sweating rate that loses salt, the prevalence of hyponatremia in hospitalized patients over the age of 60 was as high as $25 \%$ (4). Hyponatremia is also associated with diuretic treatment $(5,6)$.

The prevalence of hyponatremia should highlight the magnitude of the problem and should prompt health-care professionals to investigate and treat these patients and terminate low salt diet if being adopted by elderly and chronic sick individuals to their detriment. Low salt diet is associated 
with increased mortality and has been heavily criticized in the US press and the Lancet (7). As long as sodium excretion is normal, a high salt diet is safe; if such excretion is excessive, as is often the case in the elderly, low salt diet is very dangerous. In subjects with normal or increase $\mathrm{Na}^{+}$excretion, an increase salt intake could improve the quality of life.

Squecco et al. (8) have recently reported detrimental effects of hyponatremia on two different neuronal cell lines, SK-N-AS and SH-SY5Y, independent of osmotic alterations. They made experiments in low sodium medium either in hypo-, hyper-, or iso-osmotic conditions, for a short ( $24 \mathrm{~h}$ ) or long time (7 days). Their results indicate that cell capacitance and membrane conductance increase regardless of osmolarity, but such effects are differently dependent on time in culture. Relevant to the mechanisms involved in maintenance of cell capacitance and membrane conductance in hyper-osmotic medium, they also observed a greater contribution of the sodium-calcium exchanger with respect to hypo-osmotic medium and control. In view of these fundamental changes in basic neuronal electrophysiology induced by hyponatremia, and the basic fact that depolarization is a sodium-dependent function in electrically active cells, e.g., heart, vascular smooth muscle, and skeletal muscle, we can only emphasize the need to avoid hyponatremia at all cost.

\section{THE INCREASING PREVALENCE}

There are an increasing number of reports of the rising prevalence of hyponatremia, e.g., Nair et al. (9), Lobo-Rodríguez et al. (10), and Gandhi et al. (11) even in children (who surely should not be given a low salt diet) (12), including neonates (13) and athletes who drink too much water when losing salt through sweating $(14,15)$. Pituitary deficiency of ACTH $(16)$, subarachnoid hemorrhage (17), osteoporosis, failure of salt supplementation with medical treatments (18), thiazide treatment in the elderly (19), and thiazide and psychotropic drugs combined (20) have all been associated with severe hyponatremia. When these conditions occur in a population on low salt intake, a considerable possible risk may result in unnecessary morbidity, mortality, and strain on health services.

\section{THE STATE ADVICE TO POPULATIONS TO ADOPT THE LOW SALT DIET, I.E., SHOULD NORMAL PEOPLE EAT A LOW SALT DIET?}

Many states advise their populace to eat a low salt diet, an advice that is based on the many studies, indicating that this will save lives (21-27). We protest about the spurious argument that salt intake has increased in recent times (28). The historical evidence is quite opposite, as early civilizations, the Navy, and housewives have until recently used salt for preserving food. The most precious gift a guest could offer his host in previous civilizations was "bread and salt." Now, with food being preserved in freezers, salt intake has decreased. The debate continues $(28,29)$.

Meta-analyses of trials in normotensive subjects are similar to prospective studies in estimating a $1.7 \mathrm{mmHg}$ rise per $100-\mathrm{mM}$ increment in urinary 24 -h sodium excretion, but prospective studies relating health outcomes to 24 -h sodium excretion produced inconsistent results (30-32). The fall in BP with salt restriction may be greater in patients with diabetic kidney disease than in normals (33). In a very large study in European White ethnic subjects, in whom sodium intake was accurately assessed by measuring 24-h urinary sodium output, no correlation between salt intake and blood pressure was shown (34), suggesting that the earlier studies on mixed ethnic populations were unsound, as salt sensitivity varies in various populations (2). When normal people with normal renal function ingest sodium, any excess is excreted in the urine, and total body sodium remains normal (35). The issue of whether nations should be on low salt could be decided by a double-blind controlled clinical trial of similar groups of normal people randomized to low-salt versus high-salt diet and followed up for a lifetime. The end points would be age at death, clinical hypertension confirmed by automated 24 -h blood pressure monitoring, and plasma sodium ion concentration.

In view of the personal and economic burden on health provision of hyponatremia, a wiser policy in the meantime might be for any normotensive person wondering whether to restrict their salt intake to undergo renal function tests and a salt loading test. If there is no contraindication, a normal salt diet could be prescribed with the proviso that the tests be repeated if the patient develops hypertension confirmed by automated 24 -h blood pressure monitoring.

\section{DIRECT EXPERIMENTAL EVIDENCE PERTAINING TO SALT INGESTION AND BODY SODIUM}

\section{Salt Loading}

We (36) made a statistical analysis of the salt loading study of Luft et al. (37). The relationship, of systolic BP to salt loading of 7 days, in that study showed no significance (Spearman rank correlation), until doses of over $50 \mathrm{~g} /$ day (Caucasian subjects, $n=7$ ). The other group of Afro-Caribbean subjects $(n=7)$ started to show a small increase in BP at $20 \mathrm{~g} /$ day, showing that ethnicity is important. Studies with longer periods of salt-loading and more subjects [4 weeks (38), 9 weeks (39)] found no increase in BP in normotensive and hypertensive subjects, respectively. Experimentally, high salt ingestion has no effect on blood pressure in 9 weeks, but there remains the possibility that salt loading for longer durations might cause a rise in $\mathrm{BP}$.

\section{Total Exchangeable Sodium}

The Medical Research Council Blood Pressure Group in Glasgow measured total exchangeable sodium in normals, patients developing hypertension and patients with established hypertension (40). There were no differences between the three groups. Hypertension is not associated with increased body sodium.

\section{Dietary Salt Reduction}

In order to test the idea that salt restriction would lower blood pressure, Sacks et al. (41) performed a thorough study in normotensive subjects of the effect of salt restriction and found decreases 
of average systolic blood pressure between 2.2 and $5.9 \mathrm{mmHg}$ and decreases of average diastolic blood pressure between 1.0 and $2.9 \mathrm{mmHg}$.

\section{SHOULD SALT RESTRICTION BE ADMINISTERED TO HYPERTENSIVE PATIENTS?}

In some non-Caucasian ethnic groups, the so-called "low reninhypertension" is an important, and sometimes overlooked, cause. This needs to be managed for each individual as there may be a logical decision to impose a low salt diet. The same result of the individual consultation process may be implemented in patients whose hypertension has a definable cause such as kidney disease. This situation highlights the need for people's health or health problems to be supervised for them as individuals. The great Nobel Prize laureate, Feynman (42), deprecates politicians making generally applicable policies based on only one side of a scientific argument and not necessarily applicable to all individuals.

The commonist underlying metabolic abnormality in hypertensive patients is insulin resistance or "metabolic syndrome," frequently accompanied by obesity. In these patients, high blood pressure responds satisfactorily to weight reduction (43). It can safely be assumed that weight reduction, particularly carbohydrate intake reduction, is also an effective treatment for the insulin resistance. There is evidence to suggest that $\mathrm{BP}$ is lowered in hypertension by Mediterranean and Nordic diets (44); so it will be extremely difficult to separate the effect of low salt from all the other ingredients of diet that may lower BP.

It is unusual for salt restriction to be necessary in the treatment of clinical hypertension. In the typical patient in Europe, the key to clinical management is the relationship between sodium and the renin-angiotensin system $(45,46)$. In these patients, who are the majority, suppression of the activity of the renin-angiotensin system by angiotensin-converting enzyme (ACE), or angiotensin II receptor antagonism, is effective in both controlling the BP and reducing the complications of hypertension. Diabetes also occurs in the insulin resistance triad of obesity/hypertension/ diabetes, but salt restriction makes diabetes worse (2). It is illogical for such patients to also indulge in salt restriction, unless they have kidney disease, so doctors do not recommend it. Perhaps salt restriction not supervised for the individual by his doctor contributes to the increasing prevalence of hyponatremia in

\section{REFERENCES}

1. Mitchell AR. Physiological aspects of the requirement for sodium in mammals. Nutr Res Rev (1989) 2:149-60. doi:10.1079/NRR19890012

2. Gupta N, Jani KK, Gupta N. Hypertension: salt restriction, sodium homeostasis, and other ions. Indian JMed Sci (2011) 65:121-32. doi:10.4103/ 0019-5359.104787

3. Alzheimer Research Forum Live Discussion: sports concussions, dementia, and ApoE genotyping: what can scientists tell the public? What's up for research? J Alzheimers Dis (2009) 16(3):657-66. doi:10.3233/JAD-2009-1014

4. Nankabirwa H, Kalyesubula R, Ssinabulya I, Katabira ET, Cumming RG. A cross-sectional study of hyponatraemia among elderly patients with patients with heart failure, the commonist end condition of uncontrolled hypertension?

\section{WHICH POPULATIONS SHOULD RECEIVE HIGH-SALT AND WHICH LOW-SALT DIETS?}

1. Patients with low exchangeable sodium values should have a high rather than a low-salt diet, while patients with specified types of cardiovascular disease such as low-renin hypertension should be considered for low-salt diet.

2. The consequence of low salt in elderly and chronic sick can reasonably be postulated to cause increased severity of illness. A possible additional hypothesis is that low-salt diet in the not obviously ill person may induce hyponatremic illness.

3. Of particular concern in addition is the ingestion of inadequate salt intake without adequate investigation in hot climates and patients with severe cardiovascular disease and cancer.

\section{CONCLUSION}

The increasing prevalence of hyponatremia is a worrying development and an increasing burden for health services. Whether this increasing prevalence is related in any way to the increasing adoption by the population of low salt diet cannot be proved, only postulated. The relationship between salt intake and hypertension also cannot be proved, only postulated, because there is contrary evidence and a continuing debate. Low-salt diet is only recommended as treatment of hypertension in single individuals following thorough renal and endocrinological investigations. The possibility that universal low salt ingestion by the population might perhaps contribute to the prevalence of hyponatremia should be sufficient reason for such universal ingestion to be replaced by individual care of individuals by the individual's doctor.

\section{AUTHOR CONTRIBUTIONS}

MN created the basic outline, read references, discussions of content, and wrote $50 \%$ of the manuscript. $\mathrm{AD}-\mathrm{H}$ researched references in Pubmed, created table, wrote $50 \%$ of manuscript, and edited the manuscript.

heart failure in Uganda. BMJ Open (2016) 6:5. doi:10.1136/bmjopen-2015009775

5. Sonnenblick M, Friedlander Y, Rosin AJ. Diuretic-induced severe hyponatremia. Review and analysis of 129 reported patients. Chest (1993) 103:601-6. doi:10.1378/chest.103.2.601

6. Hix JK, Silver S, Sterns RH. Diuretic-associated hyponatraemia. Semin Nephrol (2011) 31:553-66. doi:10.1016/j.semnephrol.2011.09.010

7. Editorial: salt and cardiovascular disease mortality. Lancet (2011) 317:1626.

8. Squecco R, Luciani P, Idrizaj E, Deledda C, Benvenuti S, Giuliani C, et al. Hyponatremia alters the biophysical properties of neuronal cells independently of osmolarity: a study on $\mathrm{Ni}^{2+}$-sensitive current involvement. Exp Physiol (2016) 101(8):1086-100. doi:10.1113/EP085806 
9. Nair S, Mary TR, Tarey SD, Daniel SP, Austine J. Prevalence of hyponatremia in palliative care patients. Indian J Palliat Care (2016) 22:33-7. doi:10.4103/0973-1075.173954

10. Lobo-Rodríguez C, García-Pozo AM, Gadea-Cedenilla C, Moro-Tejedor MN, Pedraz Marcos A, Tejedor-Jorge A, et al. Prevalence of hyponatraemia in patients over the age of 65 who have an in-hospital fall. Nefrologia (2016) 36(3):292-8.

11. Gandhi S, McArthur E, Reiss JP, Mamdani MM, Hackam DG, Weir MA, et al. Atypical antipsychotic medications and hyponatremia in older adults: a population-based cohort study. Can J Kidney Health Dis (2016) 3:21. doi:10.1186/ s40697-016-0111-z

12. Al Shibli A, Abukhater D, Al Kuwaiti N, Noureddin MB, Al Harbi M, Al Kaabi A, et al. Hyponatraemia and neurological complications in children admitted with bronchiolitis. Paediatr Int Child Health (2016) 36(3):175-80. doi:10.1080/20469047.2016.1162390

13. Tseng MH, Lin SH, Chung HT, Hsu TC, Lien R, Huang JL, et al. Severe hyponatremia secondary to peripherally inserted central catheter in a neonate. Pediatr Neonatol (2016). doi:10.1016/j.pedneo.2015. 08.010

14. Maughan RJ, Shirreffs SM. Dehydration and rehydration in competitive sport. Scan J Med Sci Sports (2010) 20(Suppl 3):40-7. doi:10.1111/j.16000838.2010.01207.x

15. Valentine V. The importance of salt in the athlete's diet. Curr Sports Med Rep (2007) 6(4):237-40. doi:10.1097/01.CSMR.0000306477.87713.74

16. Doroftei NA, de Rudder C, de Visscher N, Hanon F. Isolated ACTH deficiency in a patient with empty sella as revealed by severe hyponatremia. Acta Clin Belg (2016):1-4. doi:10.1080/17843286.2016.1175702

17. Mistry AM, Mistry EA, Ganesh Kumar N, Froehler MT, Fusco MR, Chitale RV. Corticosteroids in the management of hyponatremia, hypovolemia, and vasospasm in subarachnoid hemorrhage: a meta-analysis. Cerebrovasc Dis (2016) 42(3-4):263-71. doi:10.1159/000446251

18. Polák $\mathrm{P}$, Husa $\mathrm{P}$, Kubešová HM. Severe osteoporosis - the story of chronic medication-related hyponatremia. [Article in Czech]. Vnitr Lek (2016) 62(2):152-6.

19. Liamis G, Filippatos TD, Elisaf MS. Thiazide-associated hyponatremia in the elderly: what the clinician needs to know. J Geriatr Cardiol (2016) 13(2):175-82. doi:10.11909/j.issn.1671-5411.2016.02.001

20. Yoon HJ, Lee KY, Sun IO. Clinical severity of drug-induced hyponatremia: thiazides vs. psychotropics. Clin Nephrol (2016) 85(6):321-5. doi:10.5414/ CN108765

21. Mohan S, Campbell NR. Salt and high blood pressure. Clin Sci (2009) 117:1-11. doi:10.1042/CS20080207

22. He FJ, MacGregor GA. Reducing population salt intake worldwide; from evidence to implementation. Prog Cardiovasc Dis (2010) 52:363-82. doi:10.1016/j.pcad.2009.12.006

23. NICE. Cutting Salt and Fat Levels in Food Could Save Thousands of Lives. National Institute for Health and Clinical Excellence. (2011). (Press release June 25, 2010); 07/02 10:54. Available from: http://www.nice.org.uk/newsroom/news/CuttingSaltAandFatLevels.jsp

24. Institute of Medicine. Strategies to Reduce Sodium Intake in the United StatesConsensus Report. Institute of Medicine of the National Academies. (2011). (Press release April 20); 07/02 10:56. Available from: https://www.ncbi.nlm. nih.gov/books/NBK50956/

25. Bibbins-Domingo K, Chertow GM, Coxson PG, Moran A, Lightwood JM, Pletcher MJ, et al. Projected effect of dietary salt reductions on future cardiovascular disease. N Engl JMed (2010) 362(7):590-9. doi:10.1056/ NEJMoa0907355

26. Ha SK. Dietary salt intake and hypertension. Electrolyte Blood Press (2014) 1:7-18. doi:10.5049/EBP.2014.12.1.7

27. Webster J, Trieu K, Dunford E, Nowson C, Jolly KA, Greenland R, et al. Salt reduction in Australia: from advocacy to action. Cardiovasc Diagn Ther (2015) 5:207-18. doi:10.3978/j.issn.2223-3652.2015.04.02

28. Batuman V. Salt and hypertension: why is there still a debate? Kidney Int Suppl (2011) 4:316-20.

29. Simpson FO. Salt and hypertension: a skeptical review of the evidence. Clin Sci (1979) 57:S463-80. doi:10.1042/cs057463s
30. Stolarz-Skrzypek K, Liu Y, Thijs L, Kuznetsova T, Czarnecka D, Jaszcz K, et al. Blood pressure, cardiovascular outcomes and sodium intake, a critical review of the evidence. Acta Clin Belg (2012) 67:403-10.

31. Stolarz-Skrzypek K, Bednarski A, Czarmecka D, Kawecka-Jaszcz K, Staessen JA. Sodium and potassium and the pathogenesis of hypertension. Curr Hypertens Rep (2013) 15:122-30. doi:10.1007/s11906-013-0331-x

32. Stolarz-Skrzypek K, Staessen JA. Reducing salt intake for prevention of cardiovascular disease - times are changing. Adv Chronic Kidney Dis (2015) 22:108-15. doi:10.1053/j.ackd.2014.12.002

33. Suckling RJ, He FJ, MacGregor GA. Altered dietary salt for preventing and treating diabetic kidney disease. Cochrane Database Syst Rev (2010) 8:12.

34. Stolarz-Skrzypek K, Kuznetsova T, Thijs L, Tikhonoff V, Seidlerova J, Richart T, et al. Fatal and nonfatal out-comes, incidence of hypertension, and blood pressure changes in relation to urinary sodium excretion. JAMA (2011) 305:1777-85. doi:10.1001/jama.2011.574

35. Robertson JIS. Dietary salt and hypertension: a scientific issue or a matter of faith? J Eval Clin (2003) 9:1-22. doi:10.1046/j.1365-2753.2003.00359.x

36. Drake-Holland AJ, Noble MIM. Commentary: should we now abandon the low salt diet? QJM (2011) 104:1103-6. doi:10.1093/qjmed/hcr124

37. Luft FC, Ramkin LI, Bloch R, Weyman AE, Willis LR, Murray RH, et al. Cardiovascular and humoral responses to extremes of sodium intake in normal black and white men. Circulation (1979) 60:697-706. doi:10.1161/01. CIR.60.3.697

38. Kirkendall AM, Connor WE, Abboud F, Rastogi SP, Anderson TA, Fry M. The effect of dietary sodium chloride on blood pressure, body fluids electrolytes, renal function, and serum lipids of normotensive man. J Lab Clin Med (1976) 87:411-34.

39. Gros G, Weller JM, Hoobler W. Relationship of sodium and potassium intake to blood pressure. Am J Clin Nutr (1971) 24:605-8.

40. Lever AF, Beretta-Piccoli C, Brown JJ, Davies DL, Fraser R, Robertson JIS. Sodium and potassium in essential hypertension. $\mathrm{Br} \mathrm{Med} \mathrm{J} \mathrm{(1981)} \mathrm{283:463-8.}$ doi:10.1136/bmj.283.6289.463

41. Sacks FM, Svetkey LP, Vollmer WM, Appel LJ, Bray GA, Harsha D, et al. Effects on blood pressure of reduced dietary sodium and the dietary approaches to stop hypertension (DASH) diet. N Engl J Med (2001) 344:3-10. doi:10.1056/ NEJM200101043440101

42. Feynman RP. Surely You're Joking Mr. Feynman. London: Vintage Books (1992).

43. Reisin E, Abel R, Modan M, Silverberg DS, Eliahou HE, Modan B. Effect of weight loss without salt restriction on the reduction of blood pressure in overweight hypertensive subjects. N Engl J Med (1978) 298:1-6. doi:10.1056/ NEJM197801052980101

44. Ndanuko RN, Tapsell LC, Charlton KE, Batterham MJ. Dietary patterns and blood pressure in adults: a systematic review and meta-analysis of randomised controlled trials. Adv Nutr (2016) 15:76-89. doi:10.3945/an.115.009753

45. Hall JE. Control of sodium excretion by angiotensin II: intrarenal mechanisms and blood pressure regulation. Am J Physiol (1986) 250:R960-72.

46. Hall JE, Guyton AC, Mizelle HL. Role of the renin-angiotensin system in control of sodium excretion and arterial pressure. Acta Physiol Scand Suppl (1990) 591:48-62.

Conflict of Interest Statement: The authors have not received payment or services of any third party for any aspect of the submitted work and have no financial relationships with entities that could be perceived to influence or that give the appearance of potentially influencing what has been written in the submitted work. The authors have no declared or pending patents, copyrights, or royalties relevant to the work. The authors have no other relationships or activities that could be perceived as having influenced or potentially influencing what has been written in the submitted work.

Copyright $\odot 2016$ Drake-Holland and Noble. This is an open-access article distributed under the terms of the Creative Commons Attribution License (CC BY). The use, distribution or reproduction in other forums is permitted, provided the original author(s) or licensor are credited and that the original publication in this journal is cited, in accordance with accepted academic practice. No use, distribution or reproduction is permitted which does not comply with these terms. 